\title{
Role of Information Communication and Technology (ICT) in the Treatment of Brain Ailments
}

\author{
Srivastav $\mathbf{N}^{1,}$ Urooj $\mathbf{S}^{2}$ \\ ${ }^{1}$ Narayani Srivastav, Gujarat Energy Research and Management Institute (GERMI), Gandhinagar, Gujarat, India, \\ ${ }^{2}$ Dr Shabana Urooj, School of Engineering, Gautam Buddha University, Greater Noida, Uttar Pradesh, India.
}

Address for Correspondence: Narayani Srivastava. M. Tech, Senior Research Fellow, GERMI, Gandhinagar, Gujarat, India. Email: narayani.s@germi.res.in

\begin{abstract}
The emphasis on understanding the human brain and its functioning has been captivating since ages. Rising to this challenge, it gives us an insight of who we are. Significant and profound research is taking place in medical field to understand the structure and functioning of the brain in micro detailing aspect. There are many techniques and methodologies used in the study and diagnosis of brain ailments. ICT has proven to be a strong and supportive hand in this field for better understanding and analysis. In this paper the role of ICT in the field of neuro-sciences has been elaborated.
\end{abstract}

Keywords: Cognitive functions, Synapses, Neuro-informatics, Neuromorphic technology, Connectome

\section{Introduction}

There is a captivating interest taken by people and organisation world over in utilizing the potential of digital solutions to enhance physical and mental health care system [1]. The recent advances taken place in information and communication technologies can take significant lead in providing improved health care facilities in developing nations where the gap between the ratio of health professionals to the number of people requiring health support is massive [2]. ICT plays, enduring role in four architecture such as Personcentred ICT architecture, home-centred architecture, telehealth service-centred ICT architecture and health care institution centred ICT architecture [3]. In this work, use of ICT has been emphasized in preventing and treating brain diseases. In the process of evolution man has been the fittest in their survival.

They have either evolved themselves in the physical being or modified the environment to suit according to themselves. From the age of primates to homosapiens one thing which has shown remarkable change is the human brain. Initially it had massive cerebral cortex, in proportion to body size, than most mammals, and a very

Manuscript received: $16^{\text {th }}$ January 2017

Reviewed: $25^{\text {th }}$ January 2017

Author Corrected: $3^{\text {rd }}$ February 2017

Accepted for Publication: $8^{\text {th }}$ February 2017 highly developed visual system as required for substantial survival then. Gradually, steady increase in brain size was observed, particularly in the frontal lobes, which are associated with a variety of high-level cognitive functions. Cognitive functions are those functions which can be defined as the executive functions such as self-control, planning, reasoning, and abstract thought which is required in day to day life in every aspect [4]. The human brain is the most complex part of the body [5]. For ages there had been many comprehensive researches in this field yet in this zone the level of uncertainty is very high.

Though it is protected in the hard skull still it is susceptible to injuries and damages. In recent years there has been significant increase in the number of vehicular accident with subsequent brain injuries. Closed head injury are one of the most frequently occurring injury [6]. There other ailment of brain includes dysfunction of the brain or degenerative action of the brain. They can result into Parkinson's disease, Alzheimer, and Dementia. Common brain disease are complicated and complex. There is a considerable amount of challenge faced in diagnoses as well as deciding the treatment for it. Such injuries and consequences not only effect the health status of an 
individual but also socio-economic status of the family as a whole [7].

The structure and functioning of the brain are variable. For studying the various aspects of the human brain invasively, an animal are used as specimen in laboratory conditions for conducive research and studies and for non-invasive studies techniques like EEG and functional neuro-imaging is utilized. Although substantial numbers of meticulous methodology of research are employed in this field still there is a huge difference between the human brain and the other species of animal.

The reports generated from the study done on animal specimen are useful in certain areas of physical study but during the surgeries the rate of vulnerability is soaring. Patients diagnosed with any minor brain disease are also at risk because there is a major chance of losing other functionality of the body during the surgical procedure. Medical professionals, due to perplexed surgical exposure were unavailable to give proper treatment to their patients. Use of ICT in this field can give better surgical exposure and pave way for minimally invasive techniques such as endoscopy and percutaneous treatments.

Role of ICT in Surgical scenarios- A number of recent literature have enlisted the importance of ICT in surgical procedures [8][9]. ICT not only helps to target the lesion specifically but also provides a method to remove the pathology in a meticulous manner. The importance of targeted approach towards a lesion by endoscopic procedures has been given tremendous importance. As per a recent study, percutaneous biopsy under image intensifier without anaesthesia helped an individual to get rid of a disease which did not cure by medical management [10]. Use of navigated robots in total knee replacements has become a common scenario in hospitals [9]. Navigated spine surgeries using robots like Da-vinci etc is also on a rise [11]. A recent development in this case is the use of information communication to develop three dimensional implants or vertebral bodies and aid the process of screw placements in spine surgeries [12]. The day is not far when ICT will be equally important as the skill of the surgeon in performing various procedures of not only arthroplasty, spine and brain but also general surgeries.

Challenges faced- Human emotion, feelings, behaviour, understanding, decision making and many more functions are controlled by the brain. All these factors are diverse with different individuals. Although there is a significant scientific research and development leading to innovative technology, yet human brain still persists as a mystery to all. Although its robustness, well designed hierarchy, efficiency and its ability to work all its age, creativity and its judgement towards different situation, differently is amazing. No machine in the world can match this natural intelligence machine. The speed it functions is lightning. All the innovation has the mother as this human brain.

The structure of the human brain is complex. There are layers, lobes, hierarchy of connections and synapses too. All these things are present at the very compact and well-designed way. So to understand the design it requires understanding of each and every neuron present and each and every synapse generated.

\section{Discussion}

Although the development in this field is incredible yet lags in filling the gap of knowledge. In the various schools of medicine and neuro-sciences gigantic amount of study is taking place to understand the conceptual and physicality of the various modes. The diagnosis is decided on the basis of the symptoms and the syndromes of the patient. Due to the lack of essential exposure about the origin of the problem the cure and the medicine is slow and less effective. Laboratory screening test, genetic testing are the initial steps during the diagnosis process followed by X-rays and neurological examination which includes MRI, EEG, ECG Angiography, biopsy, cerebrospinal fluid analysis, CT scan.

As compared to the earlier times when the diagnosis of the disease was done by investigating the micro-parts of the brain after death, in the present time medical science is breathing in new era. Our society is increasingly influenced by the modern day innovations brought by the information and communication technology platform.

Developments due to ICT- With the emergent information and communication technologies, experimental paradigms such as marked priming and binocular rivalry has provided a technique to know better the Neural Correlates of consciousness which made possible to understand the mechanism responsible 
for the loss of consciousness during sleep and while using anaesthesia [13].Through the world in all the school of sciences and medical sciences there is a large amount of study is been done to know the root cause behind the various genetic mutation occurring and resulting in diseases. The study is also done on the patient in various brain ailments. Cloud and distributed database technology combined with internet and modem behaves as a huge knowledge bank globally where the studies of various modes of the ailment can be done and compared for better analysis. It has brought all the symptoms and syndromes and their studies together under one umbrella while keeping the details of the patient secured. Medical informatics has provided a universal biological signature [14]. With this, diseases can be flagged and known better which leads to better diagnosis and treatment.

This has provided a positive and less risk for the patients. It has also initiated personalized drug discovery. As different patients show different response to the same drugs in the same ailment. The neuroinformatics tool behaves like a connector between the data. It helps in creating the link between the reports of different patients in the database and bringing together metadata, filling the missing link, and forming a complete brain atlas [15]. Neuro-informatics is a strong tool which can mine massively for data having recurrent patterns and helps in filling the various loop holes in the knowledge of the researcher. Brain has been modelled in various computing techniques [16].

High power computing model can provide a solution to known the minor details of the brain and its sub parts. These models are made in such a way that they can represent the entire working of the motor and sensory nerves, occurrence and stimulation generated by the synapses in the neurons present deep within forming the basic structure inside it.

They can also give multiple models to understand the problem in one phase with different ideologies and providing heterogeneous data mining and compacting. This can also help in identifying the gaps to be filled in the experiment and also to identify the constraining parameters that are yet to be measured and compared in it. New neuromorphic technologies is a hardware developed based on the functioning of the brain. It allows implementing the various brain models in the low power devices like robots etc and giving an overview to understand the simulation of the brain under various cognitive capabilities and its behaviour and understanding of the changing environment. 3D mapping of the brain genes are providing another level of analysis. It has begun progressive exploration of the neurons connecting to other neurons and the connectome.

A Connectome is a comprehensive map of neural connections in the brain. It gives a detailed map of neurons and synapses giving elaborate explanation of the functional and structural connectivity between all cortical areas and subcortical structures. The development in the field of Imaging has given an upper hand to the surgeons globally. It provides the image of the brain dissected in manifolds to study and getting the accuracy too finest level during the surgeries.

\section{Conclusion}

The development in the field of information and communication started in 1950s. Since then it has geared up in every field. The three major goals achieved by the ICT in human medical care have already been identified such as patient-centred recording and use of medical data for co-operative care, process-integrated decision support from available medical sources, comprehensive patient data which can be used for research and development purposes (Health care in the information society: A prognosis for the year 2013). As per the report ICT and medical knowledge can take a leap together. Human brain has always inspired the innovation in machines [17].

The computing techniques, programming languages and software like artificial neural network are inspired from the functioning of the brain [18]. They can provide virtual models which can be of credible assistance while studying and diagnosing a brain ailment. It could be of great help in the treatment as well. Hence role of ICT in the treatment of brain ailment is remarkable and it will initiate a new era of innovation in the neuro-science field.

\section{Funding: Nil, Conflict of interest: None.}

Permission of IRB: Yes

Financial aspects: There are no relevant financial relations in last years or near future.

Acknowledgement: The authors would like to acknowledge the faculty, staff and students at GERMI, Gujarat and Gautam Buddha University, Uttar Pradesh, India. 


\section{References}

1. Black AD, Car J, Pagliari C, Anandan C, Cresswell K, Bokun T, McKinstry B, Procter R, Majeed A, Sheikh A. The impact of eHealth on the quality and safety of health care: a systematic overview. PLoS Med. 2011 Jann 18; 8(1) :e1000387.doi: 10. 1371/journal. pmed. 1000387.

2. Lucas $H$. Information and communications technology for future health systems in developing countries. Soc Sci Med. 2008 May; 66 (10):2122-32. doi: 10.1016/j. socscimed. 2008.01.033. Epub 2008 Mar 14.

3. Haux R, Howe J, Marschollek M, Plischke M, Wolf K-H. Health-enabling technologies for pervasive health care: on services and ICT architecture paradigms. Informatics Heal Soc Care [Internet]. 2008 Jan 12 [cited 2017 Feb 6];33(2):77-89. Available from: http://www. tandfonline. com/ doi/full/10. 1080/ 17538150802127 140.

4. Culham JC, Kanwisher NG. Neuroimaging of cognitive functions in human parietal cortex. Curr Opin Neurobiol. 2001 Apr;11(2):157-63.

5. Sporns O, Zwi JD. The small world of the cerebral cortex. Neuroinformatics. 2004;2(2):145-62.

6. Goel S, Goel SA, Bhavsar NM, Makwana H, Lil NA, Patel PR. Epidemiology and patterns of lower limb injuries at a tertiary care hospital in Ahmedabad. Int $\mathbf{J}$ Med Res Rev [Internet]. 2015 [cited 2016 Dec 31];3(5). Available from:http://medresearch.in/index.php/ IJMRR /article/view/294.

7. Goel S, Modi H, Dave B, Patel P. Socio-Economic Impact of Cervical Spinal Cord Injury Operated in Patients with Lower Income Group. Glob Spine J [Internet]. 2016 Apr 4 [cited 2016 Dec 31]; 6 (S 01): GO264. Available from: http://www.thieme-connect. de /DOI/DOI?10. 1055/s-0036-1582921.

8. Kim HJ, Kang KT, Park SC, Kwon OH, Son J, Chang BS, Lee CK, Yeom JS, Lenke LG. Biomechanical advantages of robot-assisted pedicle screw fixation in posterior lumbar interbody fusion compared with freehand technique in a prospective randomized controlled trial-perspective for patientspecific finite element analysis. Spine J. 2016 Nov 17. pii: S1529-9430(16)31094-4. doi: 10.1016/j.spinee. 2016. 11.010. [Epub ahead of print].

9. Niehaus R, Schilter D, Fornaciari P, Weinand C, Boyd M, Ziswiler M, Ehrendorfer S. Experience of total knee arthroplasty using a novel navigation system within the surgical field. Knee. 2017 Jan 20. pii: S09680160 (16) 30189-2. doi: 10.1016/j. knee. 2016. 10.021. [Epub ahead of print].

10. Goel SA, Modi HN, Desai YJ, Thaker HP. A Rare Case of Pheohyphomycotic Lumbar Spondylodiscitis Mistreated as Koch's Spine. Case Rep Orthop. 2016; 2016: 8705204. doi: 10.1155/2016/8705204. Epub 2016 Dec 18.

11. Duan Q, Du Z, Yu H, Wang Y, Dong W. Error Analysis and Experimental Study of a Bi-Planar Parallel Mechanism in a Pedicle Screw Robot System. Sensors [Internet]. 2016 Nov 30 [cited 2017 Feb 6]; 16 (12): 2022.

12. Phan K, Sgro A, Maharaj MM, D'Urso P, Mobbs RJ. Application of a 3D custom printed patient specific spinal implant for C1/2 arthrodesis. J Spine Surg. 2016 Dec; 2(4):314-318. doi: 10.21037/jss.2016.12.06.

13. Seth AK, Edelman GM. Consciousness Consciousness and Complexity Complexity. In: Encyclopedia of Complexity and Systems Science [Internet]. New York, NY: Springer New York; 2009 [cited 2017 Feb 6]. p. 1424-43. Available from: http://link.springer.com/10.1007/978-0-387-30440-3_94

14. H.L.Atwood. The Biology of Crustacea: Volume 3: Neurobiology, Structure and Function - Gerard Meurant - Google Books [Internet]. [cited 2016 Dec 31]. Available from: https://books.google.co. in/books?hl $=$ en $\& \mathrm{lr}=\& \mathrm{id}=\mathrm{y} 6 \mathrm{~d} 7 \mathrm{o} \mathrm{Ko} 700 \mathrm{gC} \& \mathrm{oi}=\mathrm{fnd} \& \mathrm{pg}=\mathrm{PA} 105 \&$ $\mathrm{dq}=$ synapses+and+neurotransmitters\&ots $=0 \mathrm{y} 0$ nqe_6Zb \&sig=-aizI0LitFKy5-as0TGO 1yB8zV4\#v=onepage \& $\mathrm{q}=$ synapses and neurotransmitters $\& \mathrm{f}=$ false

15. Shepherd GM, Mirsky JS, Healy MD, Singer MS, Skoufos E, Hines MS, Nadkarni PM, Miller PL. The Human Brain Project: neuroinformatics tools for integrating, searching and modeling multidisciplinary neuroscience data. Trends Neurosci. 1998 Nov; 21 (11): 460-8. 
16. Plakitsi K. Rethinking the Role of Information and Communication Technologies (ICT) in Science Education. In: Activity Theory in Formal and Informal Science Education [Internet]. Rotterdam: Sense Publishers; 2013[cited 2016 Dec 31]. p. 57-81. Available from:http://link.springer.com/10.1007/97894-6091-317-4_4.

17. Baltes PB, Lindenberger $U$. Emergence of a powerful connection between sensory and cognitive functions across the adult life span: a new window to the study of cognitive aging? Psychol Aging. 1997 Mar; 12 (1):12-21.

18. ROCO MC. Science and Technology Integration for Increased Human Potential and Societal Outcomes. Ann N Y Acad Sci [Internet]. 2004 May [cited 2016 Dec 31]; 1013(1):1-16. Available from: http://doi.wiley. com/10. 1196/annals. 1305.001.

\section{How to cite this article?}

Srivastav N, Urooj S. Role of Information Communication and Technology (ICT) in the Treatment of Brain Ailments. Int J Med Res Rev 2017;5(02):119-123. doi:10.17511/ijmrr. 2017.i02.04. 